\title{
VISIAGORA BY CLL LANGUAGE CENTRES: AN INNOVATIVE DISTANCE LEARNING EXPERIENCE AND PEDAGOGICAL APPROACH IN A VIRTUAL CLASSROOM
}

\author{
Ray Levy \\ CLL Language Centres, Belgium
}

\begin{abstract}
Providing an innovative solution for distance language learning is nowadays very challenging. The distance teachers are most of the time left alone to set up their classes and teaching material whereas learners are struggling to keep motivation at a high level.

After 2 years of research and experimentation, CLL Language Centres (associated to the Catholic University of Louvain-la-Neuve in Belgium) developed and launched an innovative solution, Visiagora, where classes are based on a communicative approach and are built up around a pedagogical structure of 30 minutes in a virtual classroom: learners benefit of the experience of a short but intense one-on-one class with the features of a physical classroom but are taking their language course from the comfort of their home or office. As a result, the learning experience and motivation is increased and the foreign language acquisition becomes more efficient.

This paper goes through the innovative and communicative pedagogical approach and structure of our 30-mn classes: they are composed of 7 phases (introduction, lesson overview, comprehension activity, consolidation activity, presentation activity, production activity and delay correction \& summary). It also develops the features of our virtual classroom and whiteboard, which enable the learners and teachers to benefit from all the features of a physical classroom. To conclude, the learning and teaching experiences from the perspective of learners and teachers are presented.
\end{abstract}

\section{KEYWORDS}

Distance Learning, Virtual Classroom, One-On-One Classes, Innovative Pedagogy

\section{INTRODUCTION}

Technological development has resulted in new consumption patterns and the world's population being increasingly connected. Changing consumption patterns (with a focus nowadays on flexibility, immediacy and availability) are also present in the world of education and training. Developments in the way content is provided is a core part in this movement.

Online training, it often noted, takes place almost entirely asynchronously however we believe it is essential to offer synchronous training in the model of distance learning. For this reason, CLL developed and launched Visiagora, a unique distance learning solution in Europe.

\section{VISIAGORA}

CLL Language Centres was founded by the Catholic University of Louvain (UCL) in 1984. Since then, we have been providing language training to over 25,000 people each year in 37 languages.

In 2018, after 2 years of extensive research on technological and pedagogical innovation and thanks to our 30-year expertise and experience, we launched Visiagora; a high-performance and unique solution in Europe that represents a major asset in the learning process allowing students to follow language classes from anywhere and at any given time. 
Visiagora presents a strong solution towards language learning via an online platform. While innovative due to its pedagogical and technical aspects, the platform also offers tailor-made language training enabling learners to achieve their objectives, live and online, whenever and wherever they wish. The platform incorporates all the tools necessary for a user-friendly experience; an intuitive dashboard on which learners can access the profiles and calendars of teachers, book their live online classes, manage class bookings and access the virtual classroom.

The virtual classroom is notable for its ease of use and efficiency, which is inspired by classroom teaching while facilitating interaction. The virtual classroom features an interactive whiteboard, a chat room, innovative teaching materials and the ability to interact orally and visually with the teacher. It is a comprehensive tool, easy to use yet powerful, and that requires no installation or plugin. Only an internet connection and a computer with a webcam, microphone and speakers are necessary.

\section{PEDAGOGICAL APPROACH}

\subsection{Vision}

\section{- Tutoring}

Our research demonstrates that almost half of learners do not complete their training if they are not accompanied by a teacher. A digital tool is thus only useful if it is well directed and can become meaningless without teachers' active intervention. Tutor intervention is therefore an essential part of live online learning and increases the completion rate of online courses.

- Tailor-made

The primary factor encouraging learners to pursue training is the link with a specific issue or need. Additionally, most learners are encouraged by the availability of self-service learning at any moment. Learners increasingly want personalised and relevant pathways for their learning needs, and are willing to take responsibility for their training, and to access it when they see a pertinent need.

- Commitment

Quality of content encourages learners to complete and return to their training. Interactivity, pedagogical approach, teacher quality as well as the overall user experience are important factors.

Visiagora's pedagogical approach is therefore based on the following concepts. Learners:

1. interact with expert native-speaking teachers.

2. are exposed to authentic tasks and to a variety of creative activities.

3. are guided through the learning process.

4. work in a positive atmosphere.

5. autonomy is encouraged.

\subsection{Course Organisation}

\subsubsection{Placement Test}

Beginning their course, learners undergo CLL's placement test to determine their level according to the Common European Reference Framework for Languages. This initial test has two purposes: to assess the candidates' current levels of knowledge and to test their motivation.

The language test consists of five parts (grammar, vocabulary, written expression, listening comprehension and oral expression), four of which are interactive and electronic (adaptive online test), and one happens during the first live class. This allows Visiagora to validate the learners' levels but also to set up ice-breaking activities ensuring learner-teacher cohesion. Teachers also identify learners' strengths and progression of learning. 


\subsubsection{Live Online Class}

The classes take place in our virtual classroom and last 30 minutes. Individual class sessions are scheduled between learners and teachers via teachers' calendars, accessible online using our platform.

\subsubsection{Evaluations}

Teachers query learners during the fifth class to gather their opinions on the course and to ensure that the training corresponds to their expectations: this allows to rebalance the work required for each linguistic skill and to review the strategies adopted until then.

To allow learners to assess their progression, teachers regularly organise ungraded evaluations: those are simulations in which learners are brought to reinvest the communicative and linguistic elements seen in class. Learners also perform a self-evaluation that allows them to reflect on their progress, difficulties and overall satisfaction. Teachers may also mention any successes, areas of progress and means to be put in place to facilitate the consolidation of the language.

An evaluation test is organised at the end of the cycle. The test is carried out by teachers and concerns the content of the program followed by learners. It determines whether learners have achieved the objectives that were set according to their level. Similarly, to the placement test, the evaluation test consists of a series of varied and calibrated exercises that define learners' levels in oral comprehension, written comprehension, written expression, oral expression and interaction.

\subsection{Course Structure}

\subsubsection{Participation}

Learners are considered as actors in their own learning, progress and areas of improvement. They are active participants in the progression of their courses, taking part into the preparation process, thus becoming more responsible and more motivated.

Teachers' role is no longer limited to the transmission of knowledge. They also accompany, guide, support and encourage learners in their activities. They help learners enriching their vocabulary, assist them into expressing their needs and provide constructive feedback.

\subsubsection{Session Structure}

Classes follow a specific structure:

- Phase 1: Introduction and lesson overview

This phase allows learners to feel at ease and motivate them as a mean of reassurance toward the linguistic context. In order not to discourage them, no direct corrections are made. The goal is for learners to realise that communication is possible despite errors.

The learning objectives are clearly stated and include both the content and the outcomes of the learning session.

- Phase 2: Icebreaker/starter

Icebreakers are crucial to build rapport with learners, to put them at ease and to allow teachers to start assessing the learners' levels.

- Phase 3: Comprehension activity

This consists in presenting the vocabulary that will be explored in the functional language within the lesson and establishing the semantic content of the lesson. 
- Phase 4: Consolidation activity

This is the opportunity to practice the vocabulary presented and consolidate the semantic content. This will lead into the following activity which will consolidate the language functions that have already been touched on.

- Phase 5: Presentation activity

This is the re-presentation of the key language functions and integration of new vocabulary looked at during the lesson. The grammar and vocabulary are presented as a functional tool to assist in the objective of the lesson, or, in other words, a "toolbox".

- Phase 6: Production activity

This is an opportunity to put everything together and practice speaking using the functional language and other aspects (grammar and vocabulary) of language together. This takes up most of the lesson and is the best way for learners to speak and practice what they have learnt.

- Phase 7: Delayed correction and summary

Learners are left with a good idea of what they have done and what they need to do to improve next. It starts with delayed correction and feedback on the speaking activity. This is a good opportunity for drilling and other practice. The lesson concludes with a summary of the objectives and learning outcomes.

\section{TEACHING AND LEARNING EXPERIENCES}

The advantages of Visiagora for learners are numerous. They include the automated and simplified registration and placement test, the online and fully flexible class booking, a real and complete virtual classroom, classes with qualified and experienced teachers as well as innovative pedagogy and expertise. These advantages offer the flexibility and immediacy required by learners and therefore encourage learners to commit to their learning, reinforcing their autonomy and improving their progress.

Teachers also benefit of numerous advantages: they have access to a single platform allowing them to manage their availability, access their online classes and teaching materials, and thus provide their classes from any location connected to the Internet. The structure and teaching materials necessary for a course session are fully provided and can be accessed directly online. In addition, teachers receive a full onboarding as well as ongoing professional development ensuring that they are up-to-date with Visiagora's innovative pedagogy. 